\title{
Measuring the waiting time to pregnancy with the use of a retrospective questionnaire in the course of the GGS-PL study entitled 'Generations and Gender Survey'
}

\author{
Krzysztof Tymicki
}

Instytut Statystyki i Demografii, Szkoła Główna Handlowa w Warszawie, Warszawa

Address for correspondence: Krzysztof Tymicki, Instytut Statystyki i Demografii, Szkoła Główna Handlowa wWarszawie, 02-513 Warszawa, ul. Madalińskiego 6/8, phone 2256492 75, krzysztof.tymicki@sgh.waw.pl

\section{Abstract}

Paper analyses relationship between age at first attempt to conceive and apparent fecundability defined as detection of a pregnancy. The purpose of the analysis is to account for biological consequences of age shifts on fertility schedules in contemporary low fertility societies. Age specific decrease in fecundability might lead to increase in waiting time to pregnancy measured as interval between onset of deliberate attempt to conceive and actual pregnancy. Analysis is based on retrospective measurement of waiting time to pregnancy (WtP) implemented in GGS-PL survey. Analyses reveal significant increase in WtP among women aged 35+ and only a slight increase for those aged 30-35. Due to increase in age at first reproduction we expect that share of couples having prolonged WtP or those remaining childless might increase in the future especially among social groups which are in the avant-garde of fertility postponement.

Paper addresses an issue whether increase in age at first attempt to conceive among females might have an effect on likelihood of conception. Since postponement of reproduction seems to be almost universal feature of contemporary developed societies paper aims at measuring safe limits of postponement in which conception will not be endangered by a significant drop in fecundity. Analysis uses data on waiting time to pregnancy (WtP) to measure an impact of reproductive ageing on length of interval between first attempt to conceive and conception. Methodology of measuring WtP has been implemented in Polish GGS survey. Analyses reveal significant increase in WtP among women aged 35+, slight increase among females aged 30-35 and no decrease for younger females. Results suggest that postponement of reproduction beyond age 35 might decrease chances for achieving desired number of children during lifetime and ultimately increase observed proportion of childless females.

Paper addresses an issue whether decrease in female fecundity (reproductive senescence) during life cycle might have an influence on realization of fertility intentions. Increasing age at first attempt to conceive might translate into lower than planned number of offspring due to divergence between lifecycle of modern females and changes in fecundity over the life course. We use waiting time to pregnancy (WtP) to account for impact of reproductive ageing on length of interval between first attempt to conceive a child and actual pregnancy. This retrospective methodology reflects definition of sub-fertility and infecundity as number of months with regular unprotected intercourse ending (or not) in pregnancy. Methodology of measuring WtP has been implemented in Polish GGS survey and contains questions about infertility and number of menstrual cycles needed for conception. Analyses reveal significant increase in WtP among women aged 35+, slight increase among females aged 30-35 and no decrease for younger females. Estimates of infertility yields around 6\% for females and around 3\% for males (as declared by respondents). These results are in line with results of other studies which suggest that postponement of reproduction beyond age of 35 might influence probability of conception (as well as transition to higher parities) and increase chance of remaining childless. Taking into account age patterns of fertility in Poland, reproductive senescence might not have a great impact on realization of fertility intentions on the level of general population. However, due to increase in age at first reproduction we expect that share of couples having problems with conception (prolonged WtP) might increase in the future especially among social groups which are in the avant-garde of fertility postponement.

Key words: childlessness, conception, fecundity, fertility, pregnancy, postponement, WiP

Stowa kluczowe: bezdzietność, ciąża, czas oczekiwania na ciąże, dzietność, płodność, odraczanie macierzyństwa, zapłodnienie 


\section{Introduction}

Literature on the subject defines the waiting time to pregnancy ${ }^{1}$ as the interval between the conscious attempt to have a baby and the conception itself [1-4]. The practice of measuring waiting time to pregnancy is based on using a short questionnaire, with respondents individually determining the interval between the conscious attempt to have a baby and the moment the female partner became pregnant $[5,6]$. This is the most commonly-used agent - so-called retrospective measurement, in which respondents are asked to recall certain events from the past in order to determine the number of months between the two events [3]. Measuring the waiting time to pregnancy is crucial not only due to its considerable value in studies on infertility and sterility [7], but also because of the increasing interest of demographers analysing the influence of changes in individual procreative behaviours, based on actually realised fertility plans [8]. Demographic literature combines both these aspects, as researchers are interested in the relationship between delaying the decision to attempt to have a baby and the decrease of fertility due to age, which can be reflected not only in the longer waiting time to pregnancy, but also in the above-mentioned inability to realize procreative intentions $[9,10]$.

Taking into consideration the implications of waiting time to pregnancy, both for the medical sciences as well as demographics, this paper shall focus on the two most fundamental study objectives. Firstly, a description of the methodology used to measure waiting time to pregnancy based on the retrospective questionnaire, with a presentation of the results of two stages of the 'Generations, family and cultural gender' study conducted by the Institute of Statistics and Demography at the Warsaw School of Economics [11]. Secondly, a presentation of the results of the analysis of the relation between the age of the women at the moment they began attempting to become pregnant, and the waiting time to their pregnancy. The main hypothesis assumes that waiting until a later age before beginning to attempt to have the first child will lead to prolonged waiting time to pregnancy. Taking demographics into consideration, this situation might result in the lack of possibility to achieve the preferred fertility (the second child), which in extreme cases can lead to a state of childlessness.

\section{Measuring waiting time to pregnancy: definitions and methodology}

Measurement of the waiting time to pregnancy has its origins in the definition of infertility, a term used to describe people with a permanent inability to produce offspring. As defined by the World Health Organization, infertility should be understood as a situation in which it is impossible to conceive a child (become pregnant), to maintain a pregnancy, or to carry a pregnancy to live birth despite 12 months of regular sexual intercourse, 3 to 4 times a week without any contraceptive agents [12]. In other cases, we can talk about infertility as being the prolongation of the time between the moment of beginning to attempt to have a child, and the moment of becoming pregnant - assuming that sexual intercourse is regular and unprotected [13-15].

When confronting these definitions with the results obtained from empirical studies, and assuming that the couples had regular sexual intercourse, it has been determined that insemination should occur in about $80 \%$ of couples within 6 months, whereas the remaining 20\% can reveal a slight degree of infertility. After a period of 12 months, this second percentage should reach close to $10 \%$, whereas after 48 months we should see about $5 \%$ sterile couples. Hence, limited fertility shall here be seen as the prolonged interval between beginning to attempt to conceive a baby, and becoming pregnant [15].

Taking these reflections into consideration, the following measurement of the interval was proposed: the period between the moment of undertaking a conscious attempt to have a baby (regular sexual intercourse without birth control), and the moment of insemination (to be more precise, the moment of becoming pregnant and acknowledging this fact). Literature defines this interval as the so-called waiting time to pregnancy $[1,3,16]$. What's worth mentioning here is the fact that as far as literature in English is concerned, the term "Waiting Time to Pregnancy (WTP)" is used interchangeably with the phrases "Time to Pregnancy (TtP)", and "Cycles to Pregnancy (CtP)" [1, 3].

The proposed method of measurement allows for easy identification of intervals that are prolonged due to decreased fertility, or infertility. It is important to note that this measurement is reliable only when used for couples consciously trying to conceive a baby, assuming that they are not using any contraceptive methods and are engaging in regular sexual intercourse. These are the only circumstances with which we can isolate changes in fertility according to age, with their influence on the time interval before a child is successfully conceived.

Retrospective studies are most commonly used to measure this interval. In these studies, respondents are asked to determine the number of menstrual cycles or months that passed between the moment of beginning to try to conceive a child and insemination for each pregnancy $[3,5]$. This question makes it possible to evaluate fluctuations in the fertility of couples by age, and to verify whether the length of the interval required for insemination corresponds with the aforementioned WHO definitions $[14,17]$. The fundamental advantage of the retrospective approach to studying waiting time to pregnancy is the ease of obtaining data, as opposed to the prospective method, which is not only lengthy, but also sometimes associated with the resignation of respondents from the study. Additional questions in the standard questionnaire measuring waiting time to pregnancy focus on whether partners have been diagnosed with infertility, or whether they have used any kind of help with insemination or birth control.

The underlying methodology of measurement using the retrospective questionnaire has been utilised in multiple studies. Despite the problems with its precision, authors have indicated that it stands as the only tool measur- 
ing the influence of decreased fertility on the possibility of fulfilling procreative intentions, on an individual level, across relatively large random samples $[3,5,6,16]$. (It is worth mentioning that the relations discussed herein describe matters at the individual level, hence the measurement of such relations in terms of individual respondents.

The main problems with measuring waiting time to pregnancy using the retrospective approach lie in the difficulties that respondents face when trying to specify the number of months (or menstrual cycles) essential to conceiving a baby. As can be seen from analyses focusing on the reliability of the data, respondents do not have major difficulties remembering these situations, even when they happened 20 years earlier [3]. When respondents were not sure, they were willing to group their answers in so-called knots, stating for example 'about 6 months', or 'about a year'. Furthermore, it's also worth emphasizing the need for proper selection of respondents. As far as precision is concerned, the most appropriate solution is to conduct a study on a general population, meaning couples that have already have a child or are currently expecting a baby, and couples still trying to conceive.

Another issue with measuring the interval between beginning to attempt to have a baby and actually conceiving is the notion of planning the pregnancy. The adopted methodology assumes that trying to have a baby is an anticipated process, unlike the act of conception, as this results from chance (due to ineffective prevention or complete lack of prevention), and is not correlated with the couples' plans for procreation. It has been generally presumed that accidental conception can be caused by high fertility and a lack of birth control, with simultaneous lack of intentions to procreate. This could be associated with a couple's knowledge of, or belief in, their own low fertility, or even infertility [1]. Taking precise measurements in the field of fertility fluctuations into consideration, it has been suggested that waiting time to pregnancy has been measured only in the case of first pregnancies. This statement is justified by the fact that the age that a couple attempts to have a child at, and hence enter future parenthood, is of crucial significance in any future decisions on procreation. Furthermore, when a couple is trying to have a second child, we are already dealing with proven fertility, and this creates less fear that there will be problems with the conception. It is also of great significance that the couples attempting to have a second child usually experience shorter waiting time to pregnancy than couples doing their best to have their first offspring [2].

\section{Measuring waiting time to pregnancy in the demographic context}

The decrease in fertility rates observed during the second half of the $20^{\text {th }}$ century, which is relevant to the transitions described in the theory of the second demographic transition [18], is enumerated within the main areas of interest of researchers dealing with transformations in the reproduction of the general population. Delaying the decision to procreate, and hence increas- ing the average age of having a first child, is one of the main mechanisms responsible for a reduced number of births. With a reduced overall birth rate, the total fertility rate dropped to below 1.3 births per woman, which has been described as the "lowest low fertility" [19]. The reasons for - and consequences of - this phenomenon have been well acknowledged and described by demographers, mainly in the economic [20-22, 25], social [26] and cultural contexts [27]. This is in contrast to the undeniably lower number of elaborations devoted to the bio-medical outcomes of women delaying their decisions to procreate. Therefore, this article aims to fill this gap by analysing the interconnections between women postponing their decision to procreate and the possibility of their conceiving a child, and consequently, the possibility of fulfilling their procreative intentions.

It seems critical to clarify the demographic terminology describing the processes mentioned above. Demographic research literature uses the term 'fertility' to describe the intensity of the birth rate for women of reproductive age (15-49). However, this notion can also be applied to the ability to conceive a child, as well as to maintain a pregnancy, and can also be used interchangeably with the concept of procreative potential. As such, although the Polish word ptodność can be translated as the English fertility, it is actually much closer in meaning to fecundity (i.e. the capacity to conceive a child and maintain the pregnancy), than fertility, which is used in the literature to mean the birth rate intensity of live births in a given population [28].

The idea of 'procreative plans' is defined as a declaration of the anticipated number of children that the respondent (male or female) plans to achieve during their lifetime. Alternatively, 'procreative intentions' can be described as declarations of short-term plans. In this case, the declarations are about whether the respondent (male or female) plans to have children within a welldefined period of time, beginning from the moment of their interview ${ }^{2}$. With regards to 'variable fertility' and the influence it has on the actual birth rate, it is crucial to analyse the procreative intentions of people who have no children, since involuntary childlessness can impact the actual birth rate observed in the population. Surveys conducted in Europe show that childless respondents aged 20 to 28 usually declare a will to have two children [29]. A similar result was obtained after analysis of the data from the GGS-PL study, in which almost $70 \%$ of childless respondents declared the desire to have two children [30, 31].

Bearing in mind the declarative nature of the answers to questions focusing on procreative intentions, the number of children desired by respondents usually tends to be higher than the actual birth rate, as measured by the overall birth rate of the general population. This is not only caused by the declarative character of the responses. Because of the complex nature of the relations between anticipated birth rate and actual birth rate, these difference are attributed to multiple factors. These include both the overall drop in birth rate (described by the theory of the second demographic transition), as well 
as elevated procreative intentions [32]. Overstated procreative intentions might result from normative factors, such as the model of a family with two children as being the 'right' one; expectations for the role that children will play when their parents are old (a form of pension); and finally, the realisation of individual preferences stated by partners (for example, the inconsistent preferences that parents have regarding their child's gender). The distinction between the anticipated birth rate and the actual birth rate can also be attributed to the influence of economic and institutional factors. These include: low income; access to child care for 0 to 6-year-olds; employment situation; the job market in general and the eventual return to work post-birth; the possibility of combining professional work and motherhood, and the tension between the number of children in a household and fulfilment of its material aspirations [32-34].

The difference between the actual birth rate and the anticipated birth rate gains special significance in populations known for having a low birth rate, namely those in which the decision to have another (second) child can have an influence on the birth rate of that population. On one hand, this can lead to a birth rate ensuring simple generational renewal, but on the other hand it can also just be maintained at a low level [19]. A birth rate not exceeding the anticipated value and decreased fertility rates observed on the macro level as a result of the lower birth rate, are usually explained by an increase in the average age of the mothers. This is known as the 'tempo effect', and the change in the number of children born as the 'quantity effect' [35]. Parents choosing not to have subsequent children, and the continually increasing average age of mothers (caused mainly by a rise in the age of firsttime mothers), are the main sources of this decreased birth rate, both in the longitudinal and transverse approaches.

Demographic analyses of the transitions observed in fertility patterns use a research scheme based on studying the impact that social and economic factors have on the tempo effect and the quantity effect. Apart from the above, it is assumed that we could face a 'recuperation' in the number of postponed births, caused by the rise in age of first-time mothers (due to the increased fertility of older age groups). However, a complete recuperation in the rate of births deferred because of the increased age of first-time mothers would signify that it is possible to achieve an anticipated birth rate, even in situations in which women decide to have offspring later [10]. As a consequence, achievement of an anticipated birth rate would become independent of the mother's age at the time of birth of her first child, and this would de facto overlook the impact of changes in female fertility on the possibility of their having offspring. Considering all the knowledge on female fertility and how it changes over time, it can be assumed that this particular hypothesis is simply unrealistic. This is why it is of crucial importance to determine the degree to which decreased fertility can impact the ability to fulfil procreative decisions, and more importantly, the age.

The assumption that it is possible to achieve complete and utter recuperation of the rate of births deferred be- cause of the decision to attempt to have a first child and eventually obtain a desired number of children, might only be accurate in cases when the decision is not made too late. Deciding when to attempt to have a baby might be of fundamental significance to the possibility of fulfilling procreative intentions, especially when considering the negative impact a woman's age has on her chances of becoming pregnant [23]. Therefore, the presumption that after coming to a certain age women shall not be able to achieve the desired number of children due to the decrease in fertility defined as the possibility to conceive and give birth to a child is entirely legitimate.

English literature on the subject uses the term fecundity to describe fertility, which is also considered 'procreative potential' [36]. This phrase identifies the probability of becoming pregnant during a determined period of time, assuming regular sexual intercourse without birth control [37]. It is easy to see the similarity with the previously described definitions of waiting time to pregnancy as an interval between consciously attempting to have a baby and the conception itself [13].

A number of studies indicate that in the case of women postponing the decision to begin attempting to have a baby, and the resulting age-related drop in procreative potential, greater problems associated with conceiving and birth a child appear, hence prolonging the waiting time to pregnancy. As far as men are concerned, the decrease in procreative potential is unquestionably smaller $[37,38]$. For this reason, delaying the attempt to have the first baby can lead to individual consequences, in the form of lowered fertility, as well as demographic consequences, reflected in the lack of possibilities for fulfilling procreation intentions [39]. This particular relation results from changes in the probability of insemination throughout the whole course of a woman's life, from the moment she gains her sexual maturity until menopause. These changes are nonlinear, since women gain their maximum procreative potential around the age of 20-22, followed by a gradual decrease in the possibility of being inseminated until they reach the age of menopause [36]. This gradual drop in the probability of insemination is mostly related to the influence that the ageing of the organism has on the production of ova [37].

When considering the relation between fertility and the possibility of fulfilling procreative intentions in the populations of modern, developed countries, it is of crucial importance to separate the process of reproductive ageing from the ageing of other organs and the organism as a whole. Systematic longer life expectancy, being a consequence of civilizational changes, has led to a situation in which a major part of the female population enjoys good health with significantly lower fertility. This is entirely reversed in populations characterised by low life expectancy, where reproductive ageing is strictly related to the ageing of the entire human organism. Therefore, the average age in certain populations for beginning to procreate has moved forwards to a moment that was utterly unachievable in historical populations, due to their high mortality and definitely lower life expectancy. The negative outcome of this process, as far as 
modern populations are concerned, is in beginning to try to conceive children at an age when fertility is far from its optimal value [40]. It's worth emphasising here the fact that prolonged life expectancy leads to a very long post-menopausal period, which is characteristic only of humankind. This results from the above-mentioned divergence between the ageing of the organism as a whole, and the ageing of its reproductive functions [41-43].

Discussion of the ageing of the reproductive process gains significance in the context of changes in the pattern of the birth rate observed throughout the second demographic transition, which is characterised by an increase in the average age at which first children are born. When comparing the average age of these first births from the 1950 s to modern times a divergence can be seen between the optimal age for having first children, from the biological point of view, and the actual average age. During the period preceding the second demographic transition, the average age at which women gave birth to their first child fell more or less within the period of maximum procreative potential (about 20-23), whereas in 2011 the average age at which women gave birth to their first child in OECD countries came close to $28^{3}$. According to the theoretical model of female fertility, a woman is 28 when her fertility reaches nearly $80 \%$ of its maximal value $[36,44]$. In comparison, 35 -year-old women are at only $60 \%$ of their maximal procreative potential. There is a possibility that the increasing gap between optimal age and actual age might result in the fact that it will be more difficult for women to become pregnant, and that the period of trying to conceive a baby will last longer than it does in women at the peak of their procreative possibilities [24, 45].

Only recently have reflections on the influence of the drop in procreative potential on the actual birth rate begun to be the subject of interest for demographers [39, 45-47]. These studies focus on recognising the demographic and biological consequences of reproductive ageing, such as: the increased percentage of couples who cannot have offspring for biological reasons; the impact that postponing the decision to have a baby can have on the probability of insemination, and the chance to compensate for decreased fertility with the use of artificial insemination. These analyses clearly indicate that postponing the age at which one begins trying to conceive can lead to difficulties in fulfilling procreative intentions, mainly due to the fact that fertility drops with age [37, $48,49]$. Taking biological factors into consideration (the amount of produced Graafian follicles and the proportion of poor quality oocytes), the optimal age for conceiving a child falls between 18 and 31, although we can also observe a decreased number of produced Graafian follicles and a growing proportion of poor quality oocytes within this age span [48]. The period of the most intense drop in fertility falls between age 32 and 42, when the number of produced Graafian follicles and the continuously growing share of poor quality oocytes peak. Finally, after 42 , the drop in fertility becomes so obvious that the chance of insemination remains extremely low, until irregularities during the menstrual cycle and menopause appear.
As concluded by the authors of the studies cited above, the observed biological regularities indicate that ages closer to 35 are a threshold. After passing this threshold, the period of time essential to ensuring insemination can become significantly prolonged, and certain symptoms of lowered fertility, difficulties with conceiving and hence problems with fulfilling procreative intentions can appear. Because of the postponement of the average age at which women attempt to have their first child, and the pace of reproductive ageing in women from modern populations in developed countries, the authors believe it is critical to take action in order to inform public opinion about the biological consequences of late motherhood [48].

Taking into account all of these considerations, the age drop in procreative potential could impact the interval between undertaking a conscious attempt to have a child and the actual conception - the waiting time to pregnancy. This interval stands as an important constituent of the reproduction pattern, both in populations known for natural fertility as well as controlled fertility. In populations characterised by natural fertility, the waiting time to pregnancy constitutes one of the direct determinants of their birth rate [50, 51]. Modern populations are characterised by having nearly complete control over the reproductive process, severely lower birth rates and at the same time, significantly higher ages when couples attempt to have their first child. As such, the significance of the waiting time to pregnancy may differ slightly between populations. This mainly concerns whether a couple is even able to have offspring, and whether or not they'll be able to fulfil their procreative intentions.

For this reason, changes in individual decisions about when to attempt to have a baby can have a vital impact on the possibility of becoming pregnant and giving birth to a healthy child [23]. Thus, analyses focused on learning more about the biological outcomes of late motherhood could help us understand not only whether we can observe problems in women from developed countries with conceiving a child, but also whether we can expect a drop in those countries' overall birth rate due to increasing problems with becoming pregnant. These analyses would enable emphasis of the influence of biological factors on the possibility of fulfilling procreative intentions [39]. Postponing the decision to attempt to have a child can lead to late diagnosis of fertility disorders and leave less time to proceed with possible therapy, or implement assisted conception methods [47].

Because the present paper focuses on measuring the waiting time to pregnancy, the theme of demographic theories justifying changes observed on the macro level cannot be fully expanded upon here. However, this author presents a demographic perspective on the issue in an entirely separate research paper [52]. 


\section{Measuring waiting time to pregnancy in the GGS-PL study}

The described methodology underlying the measurement of waiting time to pregnancy as an interval between consciously attempting to have a child and the actual conception, was used during the first and second stages of the GGS-PL panel study by the Institute of Statistics and Demography at the Warsaw School of Economics. The study was conducted in 2011 (first stage), and 2014, and constitutes part of the international 'Generations and Gender Programme' research programme ${ }^{4}$, which analyses various factors having an influence on the relations between parents and children, as well as between people in relationships. This study explores a vast spectrum of issues, including the decision to procreate, the forming of relationships, economic activity, and standards, values and attitudes.

The module measuring the waiting time to pregnancy was included in Section 6 of a survey used in the GGS-PL study entitled 'Fertility'. This section describes the procreative behaviours of couples, the use of birth control, the waiting time to pregnancy, as well as future procreative intentions. The questions in the survey were adapted from questionnaires elaborated by other researchers $[1$, 5, 16].

Section 6 of the survey, in both its first and second stages, includes questions focused on the following issues:

1. The age of sexual initiation.

2. Birth control (methods and implementation).

3. Problems with fertility (diagnosis, treatment).

4. Waiting time to pregnancy: the number of menstrual cycles that passed between undertaking a conscious attempt to have a child and (for couples who had decided to stop using birth control), or entering into sexual relations (for couples who declared that they did not use any birth control), and actually becoming pregnant.

5. Procreative intentions.

6. Evaluation of the effect that the birth of a child (or subsequent children) has had on various aspects of the couples' lives.

7. The impact of selected factors on the decision to have a child (and for subsequent children).

8. As far as the male/female respondent is concerned, family and friends' expectations of the couple having a child.

In both stages of the study, Section 6 of the survey was addressed to women not older than 49 , and men, regardless of their age, whose partner was not older than 49 . Taking these limitations into consideration, 5,356 people answered questions from Section 6 of the survey in the first stage of the study, and 4,453 in the second stage. In terms of quantities, these values constitute $28 \%$ and $37 \%$ of the overall number of respondents respectively.

Taking into consideration the issues discussed in this paper on the number of respondents to questions about waiting time to pregnancy during the first and second stages of the study is of crucial importance. Because the question on waiting time to pregnancy was identical in both stages of the study, it is possible to perform a combined analysis of the answers given by respondents who answered the question on waiting time to pregnancy in both stages of the study. (This does not include answers provided by respondents who answered the question twice, i.e. in both stages). The table below presents a layout of the question on waiting time to pregnancy asked in both stages of the GGS-PL study. The inclusion of both the answers from both the first and second stages of the study is designed to increase the quantity of the analysed sample, and as a consequence improve the quality of the estimated survival curve by respondent age (Graph 1).

As can be clearly seen from the graph above, the majority of respondents declared conception of their baby during the first 3 months (menstrual cycles) of unprotected sex (assuming regularity of intercourse). These respondents constitute more than $70 \%$ of the people who answered the question during both stages. This percentage is compliant with the study results presented in other studies $[3,5,16]$. The focusing of the answers provided by respondents in six-month groups $(6,12,18,24)$ is not a result of the increased frequency of conceptions, but rather from the difficulty respondents had in recalling the exact duration of this time interval, and their placement of the conception close to round dates.

When analysing the data from both stages of the GGS study, it is worth emphasising the fact that during the first stage of the study the question on waiting time to pregnancy was directed only to respondents who had finally managed to conceive a child, even if it took them longer than 12 months. During the second stage of the study it was possible to introduce a question for respondents who were unable to conceive a child, despite repeated attempts. This is important as far as the methodology of the data analysis is concerned. Due to the fact that the analysis covers both stages of the study, the researchers decided to use only the information on waiting time to pregnancy up to (and including) the 18th month. This means that the analysis covers only those respondents who were actually able to conceive a child. This is a critical assumption, as in order to estimate the influence that age has on waiting time to pregnancy, the researchers used an analysis of event history, which allows for assessment of the proportion of respondents unable to conceive a baby during subsequent months after undertaking a conscious attempt to do so. When analysing the event history, the researchers had to deal with the so-called censored observation - events, the sole occurrence of which, had not been observed. In this case, the unobserved event is the conception. Because of the different construction of the questionnaire in the first and second stages of the GGS-PL study, the analysed data came only from the respondents who were able to conceive. Additionally, the period covered by the analysis was limited to 18 months, which is a slightly higher value than the threshold for diagnosing infertility assumed by the World Health Organisation. 


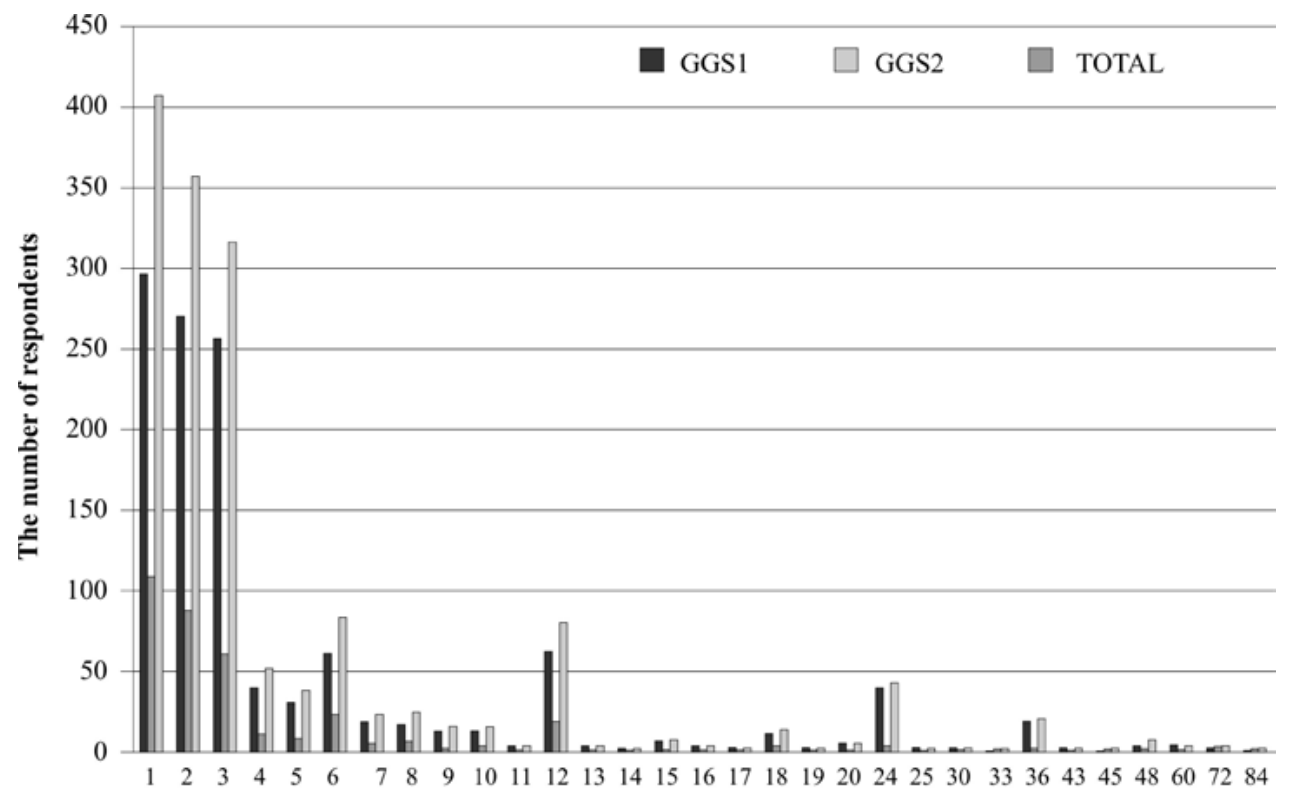

Waiting time to pregnancy in months

Graph 1. The number of respondents according to waiting time to pregnancy in months during both stages of the GGS-PL study along with the number of observations unique for both stages of the study.

Source: Own work.

\section{Results}

The Kaplan-Meier survival estimator was used to estimate the influence that a woman's age has on the interval between consciously beginning to attempt to have a child, and the conception. This method makes it possible to determine the fraction of women waiting to become pregnant from the moment of consciously be- ginning to attempt to have a baby. It can also be used to estimate the survival function, by age, of women, and additionally to determine whether a drop in fertility can have a significant influence on the duration of waiting time to pregnancy, thus making it more difficult to fulfil procreative intentions. Graph 2 shows the results of analysis of waiting time to pregnancy, by age, of women giving birth to their first child.

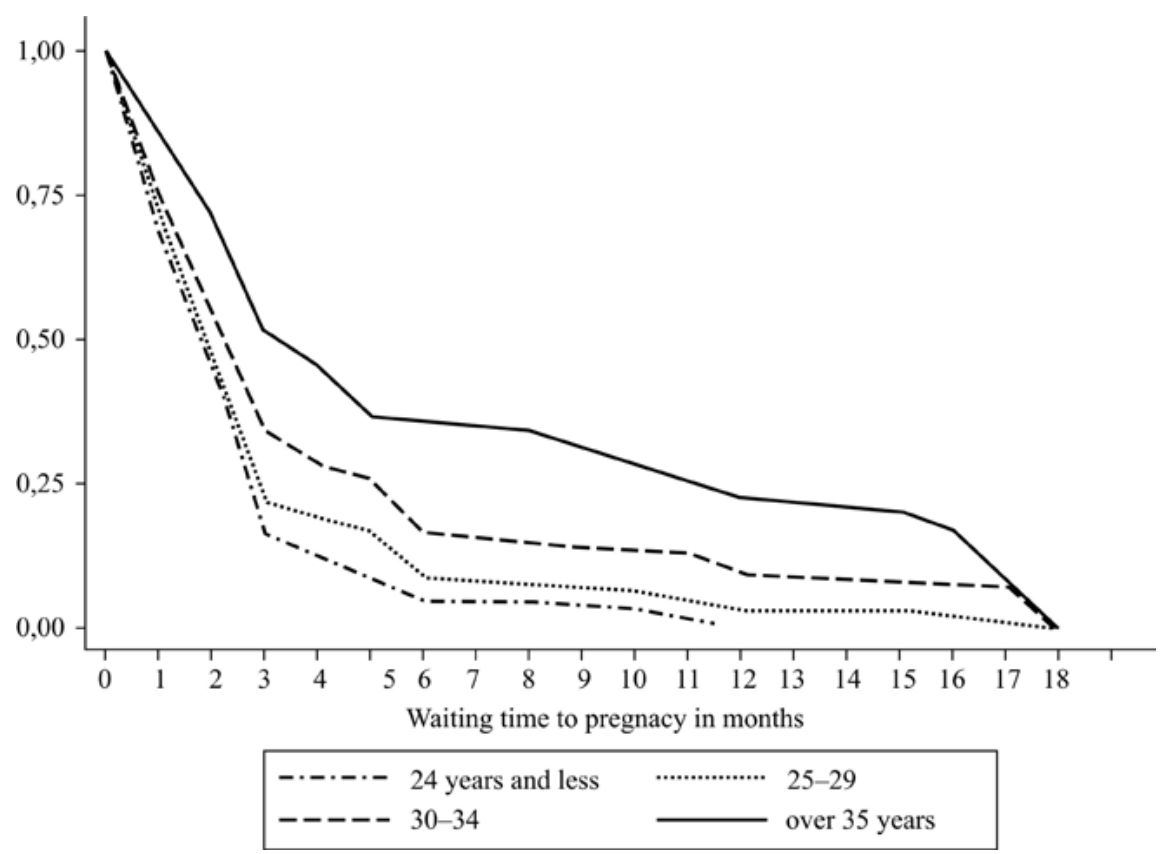

Graph 2. Waiting time to pregnancy, by mother's age, when giving birth to their first child. Estimating the survival function with the Kaplan-Meier method.

Source: Own work. 
When comparing the waiting time to pregnancy, considerable changes caused by the age of the mothers are clearly observable 5 . Nearly $25 \%$ of the women who gave birth to their first child at the age of 35 or older had to wait to become pregnant for a year or longer, whereas the analogous percentage of younger women, aged 25-29, was just $4-5 \%$. It is worth mentioning that the survival function for mothers younger than 24 , and the survival function for mothers aged 25-29, do not significantly differ. Statistically significant differences can be observed in mothers aged $30-34$, and 35 or more. Based on the results presented above, it can be concluded that women who began trying for a child after their 30th birthday should be prepared for considerable lengthening of the waiting time to pregnancy, and by the same token, for a decreased possibility of fulfilling their procreative intentions.

Another issue in studying waiting time to pregnancy is how its duration is affected by birth control methods. The existing literature concludes that use of hormonal contraception can result in prolonged waiting time to pregnancy [53-55]. However, no such dependency was observed when analysing data from the GGS-PL study [52].

\section{Discussion}

Taking into account the above-mentioned results of empirical analyses, it is crucial to state that the age-related drop in fertility might have an influence on prolonging waiting time to pregnancy. This outcome could be particularly significant for women older than 35 , and could lead to certain consequences, including (amongst others), the increased occurrence of involuntarily childless couples. Another important risk lies in late diagnosis of infertility, which then might leave not much time for medical intervention, thus also increasing the risk of involuntary childlessness. The present/GGS-PL study results make it impossible to clearly determine whether delaying the age of attempting to have a baby can impact the actual birth rate. Even so, the percentage of childless women measured as the relation between childless women in particular age groups and the overall number of women in the cohort, stands as an indirect indicator. However, this is surely an imperfect measure, since changes in this value mainly result from choice (voluntary childlessness), and not only from a lack of the biological possibility to fulfil procreative intentions.

When analysing data on the cohort birth rate of women in selected countries, an increasing percentage of childless women, aged 30 or more, can be seen (Human Fertility Database 2013). As has been shown in Graph 3, the percentage of 30-year-old childless women in Poland was close to 25\% (cohort born in 1971), and in 2009 nearly $37 \%$ (cohort born in 1979). This change results from postponement of the decision to attempt to have a baby, and at the same time indicates a considerable change in reproductive behaviours, which could impact the possibility of later fulfilling procreative intentions. At the same time, it is worth mentioning that only $15 \%$ of women born in 1966 remained childless until their $35^{\text {th }}$ birthday. The analogous percentage for women born in 1974 reached nearly $22 \%$. Comparison of the percentage of childless women aged 30 and 35 for both cohorts might show that it exactly during this particular period of life that many women make the decision to begin to attempt to have a child.

In the case of 40-year-old women it can be assumed that their procreative potential reached such a low level that the majority of them shall remain childless. In 2001 about $11 \%$ of 40 -year-old women did not have any offspring (cohort born in 1960), whereas in 2009 this number reached $15 \%$ (cohort born in 1969). It is worth emphasising that the cohort of women born in 1969 was characterised by close to $17 \%$ childlessness at the age of 35 (by 2005). This only shows that a small percentage of women conceive and deliver a child at between 35 and

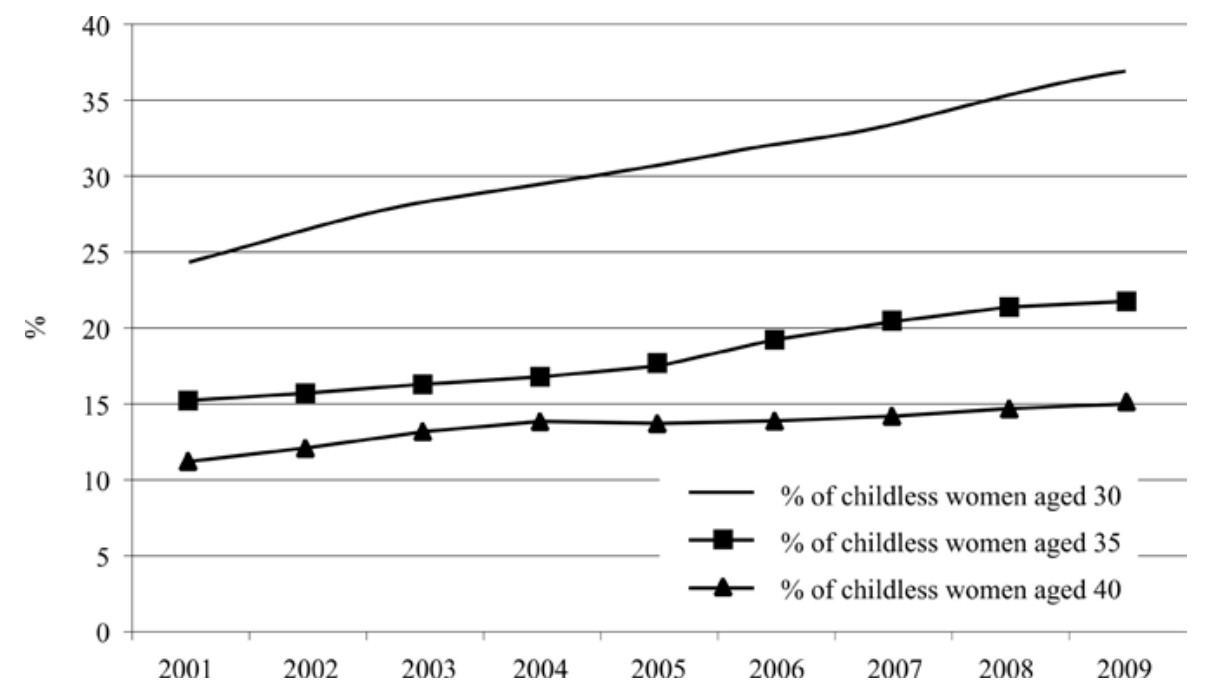

Graph 3. Percentage of childless women aged 30, 35 and 40 in Poland, 2001-2009.

Source: Individual calculations based on data from the SO birth register. 
40. It can therefore be assumed that childlessness at the age of 40 indicates an approximate percentage of women who will remain childless until the end of their life. As can be seen in Graph 3, this percentage revealed a growing tendency in 2001-2009, although the rate of this growth was slower than in the remaining age groups. The growing percentage of childless women results mainly from changes in individual approaches to starting a family, which can be observed in the delaying of the decision to procreate. In light of the presented results, this could lead to problems with becoming pregnant due to the agerelated drop in procreative potential, or a late diagnosis of infertility.

When observing trends in the proportion of childless women in selected countries, it can be seen that there is a considerable diversification in the share of childless women at age 40 in the 1969 cohort, in selected countries (Graph 4).

In Bulgaria, only $5 \%$ of 40 -year-old women were childless, whereas in Japan this percentage reached as much as $27 \%$. As far as the analyses presented in this article are concerned, the extent to which the observed childlessness results from sterility or infertility could be debated, as well as to what extent it is an outcome of individual decisions to give up motherhood. An explicit response to this question might be difficult, however, when comparing the percentage of childless 40 -year-old women in both countries - it is possible to assume that in Japan this situation results from the fact that people of reproductive age are not interested in forming relationships, and hence do not aim to have children.

It is essential to determine whether in modern, developed countries (namely those characterised by a high average age of women having their first child), the general birth rate might decrease due to discrepancies between the decision to procreate and changes in fertility. According to OECD data, the average age at which a woman has her first child is highest in countries such as Great Britain, Germany, Spain, Italy, Switzerland, Korea and Japan (close to 30), although rises in the value of this indicator are not as dynamic as they were 10 or 15 years ago $^{6}$. This could signify that the number of couples post- poning the decision to have children has peaked. Obviously, it is essential to remember that this is a value attributed to the entire population, and it can be expected that in certain social groups attempts to try having a first child might even begin much later, which may lead to even greater problems with conceiving. In order to determine the extent of the risk to the possibility of fulfilling procreative intentions caused by postponing the decision to procreate, it would be important to conduct a detailed analysis of specific, selected groups, in consideration of the variables that influence the delaying of the decision to have a child. When interpreting the data on changes in the percentage of childless women, it is crucial to remember that these changes can also be caused by an increased number of people making a conscious decision not to have offspring, and not only as a consequence of age-related drops in fertility.

Due to the descriptive character of the analyses, the obtained results could be used to conduct further, more detailed studies. An analysis focusing on the discrepancy between the biological fertility pattern and procreative behaviours in selected social groups seems to be an interesting direction for future studies. As we know, the shift in the average age for giving birth to the first child, which exceeded the age of optimal fertility (20-22), can lead to problems conceiving. Postponing giving birth to later years cannot be recovered from when trying to have a child at a later age. This mechanism of incomplete translation of anticipated birth rate to actual birth rate could also be of substantial significance as far as shaping the overall number of births in a given population. Taking into consideration the low level of the overall birth rate in Poland, it is important to pay special attention to the influence that postponing the decision to have a child can have on the possibility of fulfilling procreative intentions. According to many authors [39, 47], informative social action focusing on raising awareness of the biomedical consequences of postponing the decision to have a child could be of considerably significant help. Such action would not only raise awareness of the consequences, but also contribute to changing attitudes and procreative behaviours.

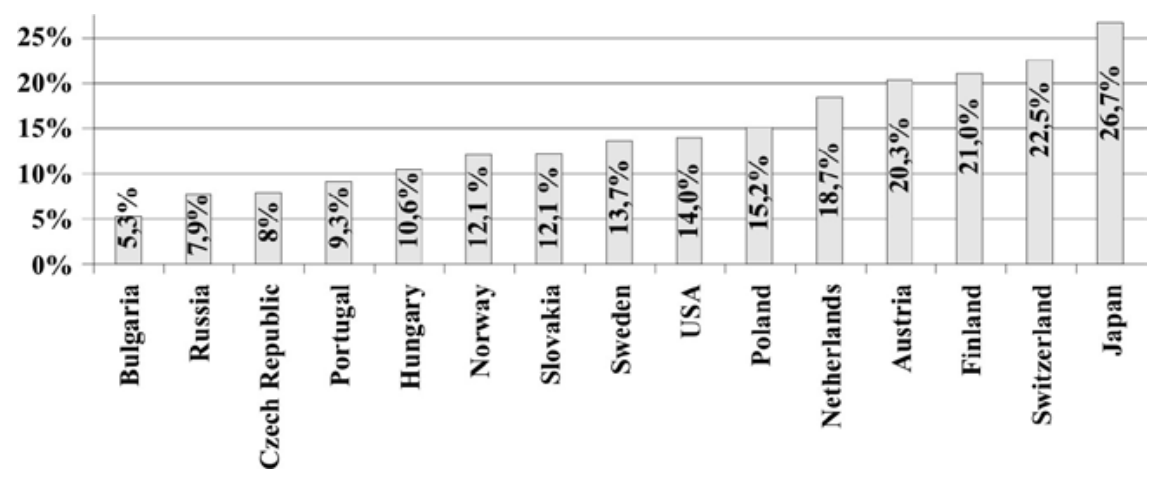

Graph 4. Percentage of childless 40-year-old women from the 1969 cohort, in selected countries.

Source: Individual calculations based on the Human Fertility Database (2013), as well as data from the SO birth register. 
In summary, it is worth emphasising that the study results presented here are the first of their kind to have been conducted in Poland on such a large representative sample. Bearing in mind the dominant demographic trends, studying the consequences of these transformations in relation to the reproductive health of the population seems truly important. The observed postponement of the procreative decision could result in a lack of possibility of having the desired number of children. Therefore, what seems crucial here is to raise public awareness of the consequences of delaying the decision to have children, not only from point of view of transforming the birth rate at the macro level, but also - and most of all - at the individual level.

\section{Notes}

1 In English it is defined as 'the waiting time to pregnancy', or 'waiting time to first conception'.

2 For example, in the GGS-PL study, respondents were asked whether they plan to have a child during the next 3 years.

3 OECD Family Database, Internet resource, http://www. oecd.org/els/soc/; accessed: September 2016.

4 http://www.ggp-i.org/

5 Statistical significance was tested at a level equalling 0.05 .

6 OECD Family Database, Internet resource, http://www. oecd.org/els/soc/; accessed: September 2013.

\section{References}

1. Olsen J. et al., Measuring time to pregnancy. Methodological issues to consider, "Human Reproduction" 1998; 13: 1751-1753.

2. Boldsen J.L., Schaumburg I., Time to pregnancy: A model and its applications, "Journal of Biosocial Science" 1990; 2 2(2): 255-262.

3. Joffe M. et al., Studying time to pregnancy by use of a retrospective design, "American Journal of Epidemiology" 2005; 162: 115-124.

4. Joffe M. et al., A time to pregnancy questionnaire designed for long term recall: Validity in Oxford, England, "Journal of Epidemiology and Community Health" 1995; 49 (3): 314-319.

5. Baird D.D. et al., Reporting errors in time-to-pregnancy data collected with a short questionnaire, "American Journal of Epidemiology" 1991; 133 (12): 1282-1290.

6. Dick M.-L.B. et al., Self-reported difficulty in conceiving as a measure of infertility, "Human Reproduction" 2003; 18: 2711-2717.

7. te Velde E.R. et al., The effect of postponement of first motherhood on permanent involuntary childlessness and total fertility rate in six European countries since the 1970s', "Human Reproduction" 2012; 27 (4): 1179-1183.

8. Billari F.C. et al., Social age deadlines for the childbearing of women and men, "Human Reproduction" 2010; 26 (3): 1-7.

9. Sobotka T. (ed.), Postponement of Childbearing and Low Fertility in Europe, Dutch University Press, Amsterdam 2004.
10. Sobotka T. et al., Postponement and recuperation in cohort fertility: Austria, Germany and Switzerland in a European context, "Contemporary Population Studies" 2011; 36 (2-3): 417-452.

11. Jóźwiak J., Kotowska I.E., Panelowe badanie przemian relacji między pokoleniami, $w$ rodzinie oraz między kobietami i mężczyznami: Generacje, rodziny i pteć kulturowa GGS-PL, "Studia Demograficzne" 2011; 159 (1): 99-106.

12. Zegers-Hochschild F. et al., The International Committee for Monitoring Assisted Reproductive Technology (ICMART) and the World Health Organization (WHO) Revised Glossary on ART Terminology, "Human Reproduction" 2009; 24 (11): 2683-2687.

13. Habbema J.D., Collins J., Leridon H., Evers J.L., Lunenfeld B., te Velde E.R., Towards less confusing terminology in reproductive medicine: A proposal, "Human Reproduction" 2004; 19 (7): 1497-1501.

14. Jenkins J. et al., European Classification of Infertility Taskforce (ECIT) Response to Habbema 'Towards Less Confusing Terminology in Reproductive Medicine: A Proposal, "Human Reproduction" 2004; 19 (12): 2687-2688.

15. Gnoth C. et al., Definition and prevalence of subfertility and infertility, "Human Reproduction" 2005; 20 (5): 1144-1147.

16. Jensen T.K. et al., Time trends in waiting time to pregnancy among Danish twins, "Human Reproduction" 2005; 20 (4): 955-964.

17. Organization, WHO, Infecundity, Infertility, and Childlessness in Developing Countries, Demographic and Health Surveys (DHS) Comparative Reports 9, 2004.

18. Van de Kaa D.J., Europe's second demographic transition, "Population Bulletin" (Population Reference Bureau) 1987; $42(1)$.

19. Kohler H.-P. et al., The emergence of lowest-low fertility in Europe during the 1990s, "Population and Development Review" 2002; 28 (4): 641-680.

20. Becker G.S. (ed.), A Treatise on Family, Harvard University Press, Cambridge 1998.

21. Ahn N., Mira P., A Note on the changing relationship between fertility and female employment rates in developed countries, "Journal of Population Economics" 2002; 15: 667-682.

22. Billari F., Kohler H.-P., Patterns of low and lowest-low fertility in Europe, "Population Studies" 2004; 58 (2): 161-176.

23. Beets G. et al., Medical Complications of Aging Fertility, in: Population and Family in the Low Countries 1993: Late Fertility and Other Current Issues, Beets G. (ed.), NIDI/ CBGS Publication Berwyn, Pennsylvania/Amsterdam, Netherlands 1994: 1-23.

24. Bianchi F.O., Campana A., The end of fertility: Age, fecundity and fecundability in women, "Journal of Biosocial Science" 1994; 26 (3): 349-368.

25. Engelhardt H., Prskawetz A., On the changing correlation between fertility and female employment over space and time, "European Journal of Population" 2004; 20 (1): 35-62.

26. Skirbekk V., Fertility trends by social status, "Demographic Research" 2008; 18 (5): 145-180.

27. Pollak R.A., Cotts-Watkins S., Cultural and econommic approaches to fertility: Proper marriage or mesaliance?, 
"Population and Development Review" 1993; 19 (3): 467-496.

28. Preston S.H. et al. (ed.), Demography. Measuring and Modelling Population Processes, Blackwell Publishers, Oxford 2001

29. Testa M.R., Women's Fertility Intentions and Level of Education: Why are They Positively Correlated in Europe?, European Demographic Research Papers, Vienna Institute of Demography of the Austrian Academy of Sciences, Vienna 2012: 3 .

30. Kotowska I.E., Jóźwiak J., Panelowe badanie przemian relacji między pokoleniami, $w$ rodzinie oraz między kobietami i mężczyznami: generacje, rodziny i płeć kulturowa GGS-PL, "Studia Demograficzne" 2011; 159 (1): 99-106.

31. Mynarska M., Kto planuje mieć dzieci w Polsce do 2015 roku?, "Studia Demograficzne" 2011; 159 (1): 75-98.

32. Toulemon L., Testa M.R., Fertility intentions and actual fertility: A complex relationship, "Population and Societies" 2005; 415: 1-4.

33. Sobotka T., The diverse faces of the second demographic transition in Europe, "Demographic Research" 2007; 19 (8): 171-224.

34. Régnier-Loilier A., Vignoli D., Fertility intentions and obstacles to their realization in France and Italy, "Population" 2011; 66 (2): 361-389.

35. Bongaarts J., Feeney G., On the quantum and tempo of fertility, "Population and Development Review" 1998; 4 (1): 105-132.

36. Wood J.W., Fecundity and natural fertility in humans, in: Oxford Reviews of Reproductive Biology, Milligan S.R. (ed.), Oxford University Press, Oxford 1989, 11: 61-109.

37. O'Connor K.A. et al., Declining fecundity and ovarian ageing in natural fertility populations, "Maturitas" 1998; 30 (2): 127-136.

38. Sartorius G.A., Nieschalg E., Paternal age and reproduction, "Human Reproduction Update" 2010; 16 (1): 65-79.

39. Schmidt L. et al., Demographic and medical consequences of the postponement of parenthood, "Human Reproduction Update" 2012; 18 (1): 29-43.

40. Kaplan H. et al., A Theory of human life history evolution: Diet, intelligence, and longevity, "Evolutionary Anthropology" 2000; 9 (4): 156-185.

41. Hill K.A., Hurtado M., The evolution of premature reproductive senescence and menopause in human females, "Human Nature" 1991; 2 (4): 313-350.
42. Shanley D.P., Kirkwood T.B.L., Evolution of human menopause, "BioEssays" 2001; 23: 282-287.

43. Hawkes K., Grandmothers and the evolution of human longevity, "American Journal of Human Biology" 2003; 15 (3): 380-400.

44. Wood J.W. (ed.), Dynamics of Human Reproduction: Biology, Biometry, Demography, Aldine de Gruyter, New York 1994.

45. te Velde E.R., Pearson P.L., The variability of female reproductive ageing, "Human Reproduction Update" 2002; 8 (2): $141-154$.

46. ESHRE C.W.G., Social determinants of human reproduction, "Human Reproduction" 2001; 16: 1518-1526.

47. Leridon H., Can assisted reproduction technology compensate for the natural decline in fertility with age? A model assessment, "Human Reproduction" 2004; 19 (7): 1548-1553.

48. Liu K., Case A., Advanced reproductive age and fertility, "Journal of Obstetrics and Gynaecolgy" 2011; 33 (11): $1165-1175$.

49. Van Geloven N.F. et al., Can we distinguish between infertility and subfertility when predicting natural conception in couples with an unfulfilled child wish?, "Human Reproduction" 2013; 28 (3): 658-665.

50. Bongaarts J., A framework for analysing the proximate determinants of fertility, "Population and Development Review" 1978; 4: 105-132.

51. Bongaarts J., The measurement of wanted fertility, "Population and Development Review" 1990; 16 (3): 487-506.

52. Tymicki K., Zamierzenia prokreacyjne a możliwość ich realizacji $w$ kontekście czynników biologicznych, "Studia Demograficzne" 2013; 164 (2): 9-31.

53. Linn S. et al., Delay in conception for former pill users, "The Journal of the American Medical Association" 1982; 247 (5).

54. Farrow A. et al., Prolonged Use of Oral Contraception Before a Planned Pregnancy is Associated with a Decreased Risk of Delayed Conception, "Human Reproduction" 2002; 17 (10): 2754-2761.

55. Hassan M.A.M., Killick S.R., Is previous use of hormonal contraception associated with a detrimental effect on subsequent fecundity?, "Human Reproduction" 2004; 19 (2): 344-351.

This article has been published as part of a project financed from resources provided by the National Science Centre, granted under decision number DEC-2013/08/M/HS4/00421.

Tłumaczenie: Małgorzata Kierska 